\title{
Differential Action of the Bisphosphonates
}

\section{(3-Amino-1-Hydroxypropylidene)-1,1-Bisphosphonate (APD) and Disodium Dichloromethylidene}

\section{Bisphosphonate $\left(\mathrm{Cl}_{2} \mathrm{MDP}\right)$ on Rat Macrophage-mediated}

\section{Bone Resorption In Vitro}

\author{
Pieter H. Reitsma, Steven L. Teitelbaum, Olav L. M. Bijvoet, and \\ ARnold J. KaHn, Department of Clinical Endocrinology, University Hospital, \\ Leiden, The Netherlands; Department of Pathology and Laboratory \\ Medicine, and the Division of Bone and Mineral Metabolism, The Jewish \\ Hospital of St. Louis, and Washington University Schools of Medicine \\ and Dental Medicine, St. Louis, Missouri 63110
}

A BSTRACT The bisphosphonates (3-amino-1-hydroxypropylidene)-1,1-bisphosphonate (APD) and disodium dichloromethylidene bisphosphonate $\left(\mathrm{Cl}_{2} \mathrm{MDP}\right)$ effectively inhibit the accelerated bone resorption associated with some skeletal disorders, e.g., Paget's disease. However, it has not been established whether these compounds exert their inhibitory effect by rendering the bone mineral more resistant to degradation, by diminishing the activity of resorbing cells, or through some combination of both activities. In this study, we have tested these possibilities using an in vitro resorption assay system consisting of elicited rat peritoneal macrophages co-cultured with particles of ${ }^{45} \mathrm{Ca}$-labeled, devitalized rat bone. This assay system permits the quantitative assessment of the action of APD and $\mathrm{Cl}_{2} \mathrm{MDP}$ on the two major phases of bone resorption (cell-substrate attachment and osteolysis) under circumstances where the drugs are present continuously or, most importantly for the issues in question, after the separate pretreatment of the particles or the resorbing cells.

Our data indicate that (a) Both APD and $\mathrm{Cl}_{2} \mathrm{MDP}$ at concentrations $\geq 5 \times 10^{-6} \mathrm{M}$ diminish macrophagemediated ${ }^{45} \mathrm{Ca}$ release (i.e., bone resorption) in a log

Received for publication 22 February 1982 and in revised form 9 July 1982.

Address correspondence to Dr. Pieter H. Reitsma, Washington University School of Dental Medicine, St. Louis, MO 63110 . dose-dependent fashion. (b) A 10-min pretreatment of bone particles with either bisphosphonate (P-C-P) similarly inhibits resorptive activity, but is most pronounced with $\mathrm{Cl}_{2} \mathrm{MDP}$. However, only APD is effective in reducing resorption when cells are preincubated (for $24 \mathrm{~h}$ ) with P-C-P. (c) In cultures containing both labeled and unlabeled bone, significant inhibition occurs only when the labeled particles are coated with P-C-P (indicating that the action of P-C-P-treated bone is highly localized). (d) P-C-P does not diminish cell-bone particle attachment, an essential step in the resorptive process. On the other hand, delaying the addition of P-C-P until after cell-bone attachment is completed significantly reduces the resorption-inhibiting effect of these compounds. (e) $\mathrm{Cl}_{2} \mathrm{MDP}$ reduces culture DNA content in proportion to its inhibitory effect on resorption, and both the inhibitory and cytotoxic actions of this P-C-P are dependent upon the presence of bone. On the other hand, APD is cytotoxic only at very high concentrations $\left(10^{-4} \mathrm{M}\right)$, acts independently of the presence of bone, and inhibits resorption without killing cells.

We conclude that the mechanisms of action of APD and $\mathrm{Cl}_{2} \mathrm{MDP}$ are markedly different. $\mathrm{Cl}_{2} \mathrm{MDP}$ is a potent cytotoxin in the presence of bone and apparently exerts its inhibitory effect in this manner. APD is noncytotoxic at levels adequate to suppress resorption and, therefore, must inhibit macrophage activity by some other mechanism. Neither P-C-P appears to limit resorption by decreasing the solubility of mineralized bone matrix. 


\section{INTRODUCTION}

Bisphosphonates (P-C-P) ${ }^{1}$ are nonbiodegradable analogues of pyrophosphate $\left(\mathrm{PP}_{\mathrm{i}}\right)$ with a high binding affinity for hydroxylapatite crystals (1). Administration of P-C-P to experimental animals rapidly curtails bone resorption (2-4), and it is for this reason that these compounds are used in the treatment of clinical disorders characterized by increased bone degradation. For example, both disodium (3-amino-1-hydroxypropylidene)-1,1-bisphosphonate (APD) and disodium dichloromethylidene bisphosphonate $\left(\mathrm{Cl}_{2} \mathrm{MDP}\right)$ are effective in decreasing bone resorption in Paget's disease and in the osteolytic lesions associated with neoplastic bone disease (5-8). Interestingly, APD effectively decreases bone resorption in vivo at much lower doses than does $\mathrm{Cl}_{2} \mathrm{MDP}$. There is no clear explanation for this difference in potency, but it may relate to the observed effects of APD on the mononuclear phagocyte system (9). Cells of the mononuclear phagocyte system (MPS) have the potential to regulate osteoclast activity (e.g., by producing prostaglandin $\mathrm{E}_{2}$ ) and APD might alter this aspect of MPS function.

The basis for the resorption-inhibiting effects of P-C-P remains unknown, but given the binding affinity of these compounds for hydroxylapatite crystals, they may well act subsequent to accumulation on bone mineral surfaces. Once present on such surfaces, they may exert their inhibitory effect by $(a)$ directly decreasing mineral solubility and ultimately the resorbability of bone matrix, $(b)$ inhibiting the attachment of osteoclasts and other potential resorbing cells (macrophages, tumor cells) to bone surfaces, or (c) diminishing the resorption-related and/or general metabolic activity of osteoclasts and other osteolytic cells. Alternatively, circulating P-C-P may act directly on cells to block cell-bone attachment or resorption, without prior binding to mineral surface.

At present, there is little information regarding the relative biological significance of each of these possible mechanisms of P-C-P inhibition. It is known, for example, that P-C-P will inhibit the growth and dissolution of hydroxylapatite crystals in vitro $(10,11)$. In addition, P-C-P have been shown to modify the metabolic activity of several different cell types grown in culture $(12,13)$. However, in none of these cases have bone matrix (or mineral) and a cell with osteolytic potential been separately treated with P-C-P and then combined in such a way as to assess the subsequent

\footnotetext{
${ }^{1}$ Abbreviations used in this paper: APD, (3-amino-1-hydroxy propylidene)-1,1-bisphosphonate; $\mathrm{Cl}_{2} \mathrm{MDP}$, disodium dichloromethylidene bisphosphonate; $\alpha$-MEM, Eagle's minimal essential medium; M $\varnothing$, adherent cell; MPS, mononuclear phagocyte system; P-C-P, bisphosphonate(s); $P_{\mathrm{i}}$, inorganic pyrophosphate.
}

action of these compounds on the resorptive process.

In this study, we have explored the mechanism of action of $\mathrm{Cl}_{2} \mathrm{MDP}$ and APD using a recently developed, macrophage-based assay system for bone resorption (14). With this system, it is possible to independently treat resorbing cells (elicited peritoneal macrophages) and bone mineral (devitalized rat bone particles) with P-C-P and to quantify the results of such treatment on the ability of the macrophages to bind and resorb bone. Our data indicate that APD and $\mathrm{Cl}_{2} \mathrm{MDP}$ do not alter the attachment of cells to bone but do inhibit macrophage-mediated resorption in a dose-dependent fashion. In the case of $\mathrm{Cl}_{2} \mathrm{MDP}$, this inhibition is bone mineral dependent, occurs primarily subsequent to the accumulation of P-C-P on the bone crystal surface, and appears to be a manifestation of the cytotoxicity of this P-C-P. In the case of APD, on the other hand, the P-C-P is cytotoxic only at high concentration, acts independently of the presence of bone and inhibits resorption, at least in part, by a mechanism not yet defined but probably dependent upon the direct action of APD on cells. Neither P-C-P appears to affect resorption by reducing the solubility of the mineral phase of bone.

\section{METHODS}

Binding and resorption assays are performed as described (14) and are summarized as follows: Elicited peritoneal adherent cells (Mø) were obtained from rats (Sprague-Dawley, $\pm 150 \mathrm{~g}) 3 \mathrm{~d}$ after a peritoneal injection with $10 \%$ Brewer's thioglycollate medium. The exudate cells were allowed to attach for $1 \mathrm{~h}$ to the wells of Costar dishes $\left(5 \times 10^{5}\right.$ cells $/ 16$ $\mathrm{mm}$ well) in $0.5 \mathrm{ml}$ modified Eagle's minimal essential medium ( $\alpha$-MEM) buffered to pH 7.4 with $3 N$-morpholinopropanesulfonic acid. The cultures were rinsed, and $\alpha-10$ medium (bicarbonate-buffered $\alpha$-MEM supplemented with $10 \%$ fetal calf serum) was added to each well. The plates were incubated at $37^{\circ} \mathrm{C}$ in humidified air and $5 \% \mathrm{CO}_{2}$ for an additional 18-23 h, and then vigorously rinsed to remove nonadherent cells. The remaining adherent cells were 9598\% macrophages as assessed by phagocytosis and nonspecific esterase staining.

Particles $(\leq 25 \mu \mathrm{m})$ of devitalized rat bone, labeled in vivo with ${ }^{45} \mathrm{Ca}$, were suspended in $\alpha-10$ medium and were added to the macrophage cultures to yield a final concentration of $0.115 \mathrm{mg} /$ well. Binding of the bone particles to the cells was assessed after $2 \mathrm{~h}$ of incubation by recovering the nonadherent particles from the culture surface and determining the isotopic content of the adherent and nonadherent particle fractions. Bone resorption (expressed as net percentage of ${ }^{45} \mathrm{Ca}$ release) was routinely determined after $96 \mathrm{~h}$ incubation from the percentage of ${ }^{45} \mathrm{Ca}$ released into the medium as a consequence of macrophage activity, and was corrected for physicochemical exchange of ${ }^{45} \mathrm{Ca}$ that occurs when bone is incubated in the absence of cells. The results of both binding and resorption assays were derived from six replicate cultures for each variable and are presented as mean \pm SEM. Experiments were generally repeated two to three times before the findings were accepted as valid.

The bisphosphonates $\mathrm{APD}$ and $\mathrm{Cl}_{2} \mathrm{MDP}$, and $\mathrm{PP}_{\mathrm{i}}$ were 
dissolved in $0.9 \%$ saline and diluted in $\alpha$ - 10 medium to the desired concentrations before addition to the cultures. Alternatively, bone particles are pretreated by incubating them for $10 \mathrm{~min}$ in solutions of P-C-P, $P P_{i}$, or phosphate buffer, resuspended in $\alpha-10$ medium and added to the cultures. Pretreatment of the M $\varnothing$ was achieved by incubating the cells for $24 \mathrm{~h}$ in P-C-P contained in $\alpha-10$ medium, and then rinsing and adding labeled bone to the cultures. Cell number and viability were indirectly assessed by measuring the DNA content of the MØ population using the ethidium bromide technique described by Karsten and Wollenberger (15).

\section{RESULTS}

APD and $\mathrm{Cl}_{2} \mathrm{MDP}$, when present throughout the entire assay period, reduced net ${ }^{45} \mathrm{Ca}$ release from the bone particles in a log dose-dependent fashion. In the representative experiment shown in Fig. 1, significant inhibition of resorption was achieved by both compounds at $5 \times 10^{-6} \mathrm{M}(P<0.01)$. The molar potency of the two P-C-P was equal. On the other hand, the passive efflux of ${ }^{45} \mathrm{Ca}$ from bone particles incubated in the absence of cells, which accounted for $\sim 20 \%$ of the radioactivity in the culture medium, was not altered by either APD or $\mathrm{Cl}_{2} \mathrm{MDP}$ (data not shown).

Inhibition of ${ }^{45} \mathrm{Ca}$ release also occurred when particles were preincubated for $10 \mathrm{~min}$ in solutions containing APD or $\mathrm{Cl}_{2} \mathrm{MDP}$ before being introduced into cultures. Using this approach, $\mathrm{Cl}_{2} \mathrm{MDP}$ was more effective, on a molar basis, than APD, whereas pretreatment in control solutions of $\mathrm{PP}_{\mathrm{i}}$ or phosphate buffer was without effect (Fig. 2). When compared with its

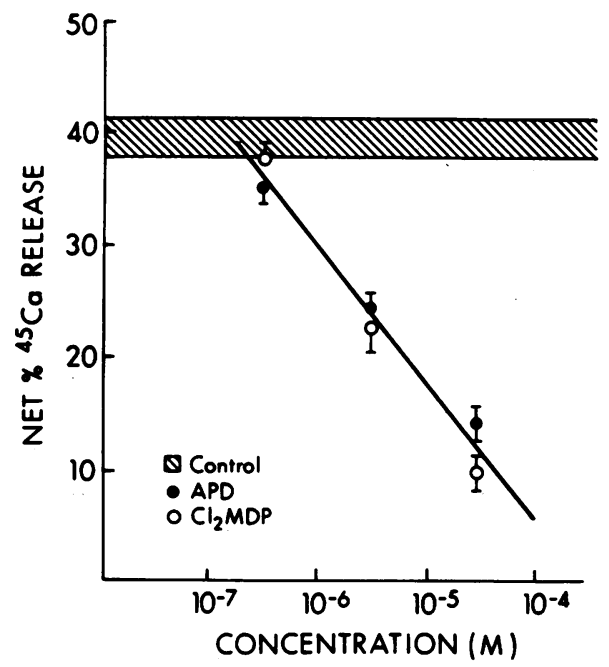

Figure 1 P-C-P inhibition of ${ }^{45} \mathrm{Ca}$ release by $\mathrm{M} \varnothing$ from devitalized ${ }^{45} \mathrm{Ca}$-labeled bone particles after $96 \mathrm{~h}$ incubation. APD and $\mathrm{Cl}_{2} \mathrm{MDP}$ were continuously present at the concentrations indicated. Net percent ${ }^{45} \mathrm{Ca}$ release was calculated by subtracting the ${ }^{45} \mathrm{Ca}$ release from cultures with bone particles only (passive efflux) from the ${ }^{45} \mathrm{Ca}$ release in the cultures containing $\mathrm{M} \varnothing$ and bone particles. All values represent mean $\pm S E M$ from six determinations.

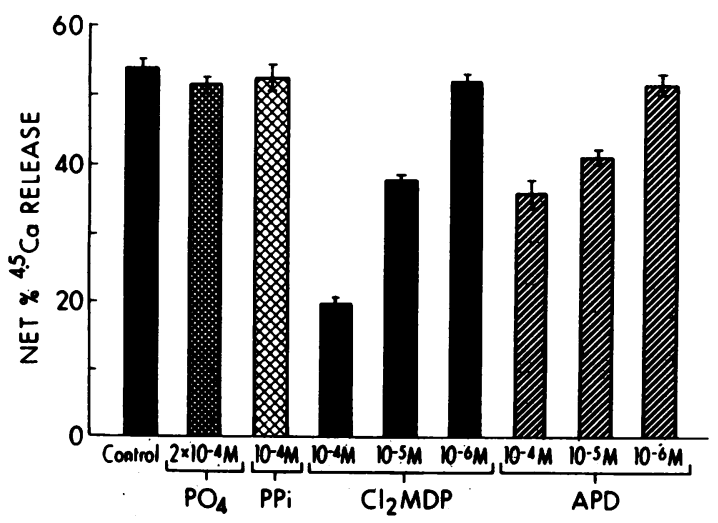

Figure 2 Effect of 10-min preincubation of devitalized ${ }^{45} \mathrm{Ca}$-labeled bone particles with APD, $\mathrm{Cl}_{2} \mathrm{MDP}, \mathrm{PP}_{\mathrm{i}}$ or $\mathrm{PO}_{4}$, on ${ }^{45} \mathrm{Ca}$ release by $\mathrm{M} \varnothing$. All values represent mean $\pm S E M$ from six determinations.

continuous presence in cultures, the dose-response curve for preincubation of bone particles with $\mathrm{Cl}_{2} \mathrm{MDP}$ was shifted to the right by about half an order of magnitude (Fig. 3). In marked contrast, only APD was effective in reducing macrophage-mediated resorption under circumstances where the cells were preincubated with P-C-P for $24 \mathrm{~h}$ (Table I).

Additional evidence for a direct involvement of bone surfaces in mediating the inhibitory action of P-C-P was obtained from experiments in which ${ }^{45} \mathrm{Ca}$ labeled and unlabeled bone were introduced concurrently into replicate $M \emptyset$-containing cultures. In some

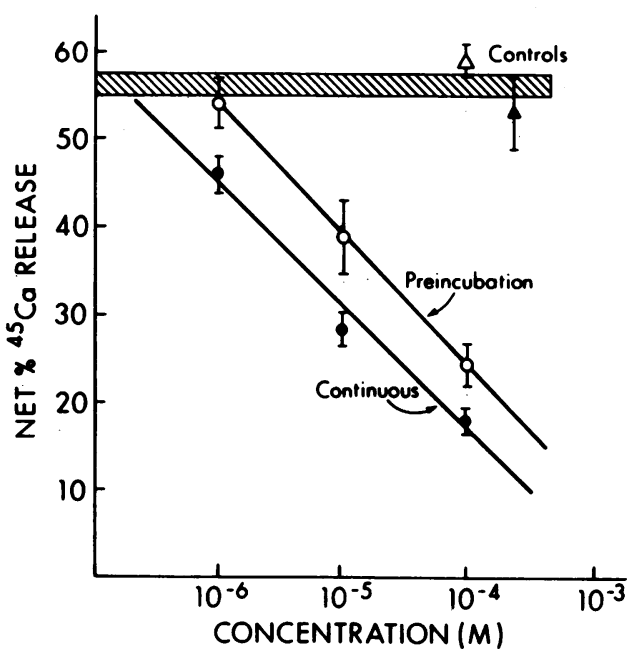

Figure 3 Comparison of bone particle pretreatment with continuous exposure to $\mathrm{Cl}_{2} \mathrm{MDP}$ on macrophage-mediated resorption. Additional controls were bone particles preincubated with $\mathrm{PO}_{4}$-buffer $\left(2 \times 10^{-4} \mathrm{M}\right.$, open triangles $)$ and $\mathrm{PP}_{\mathrm{i}}\left(10^{-4} \mathrm{M}\right.$, closed triangles). Note the relatively small difference in dose-response between the two modes of introducing P-C-P. All values represent the mean \pm SEM for six replicate cultures. 
TABLE I

Effect of $\mathrm{Cl}_{2} \mathrm{MDP}$ and $\mathrm{APD}$ on M $\mathrm{M}$-mediated Bone Resorption when M $\phi$ Were Preincubated with P-C-P for $24 h$ before the Introduction of Bone

\begin{tabular}{cc}
\hline Control & Net ${ }^{45}$ Ca release \\
\hline & $\%$ \\
& $39.5 \pm 1.9$ \\
$5 \times 10^{-5} \mathrm{M} \mathrm{APD}$ & $17.3 \pm 3.9^{\circ}$ \\
$5 \times 10^{-6} \mathrm{M}$ APD & $39.5 \pm 1.7$ \\
$5 \times 10^{-7} \mathrm{M} \mathrm{APD}$ & $37.9 \pm 1.0$ \\
$5 \times 10^{-5} \mathrm{M} \mathrm{Cl}_{2} \mathrm{MDP}$ & $43.7 \pm 2.4$ \\
$5 \times 10^{-6} \mathrm{M} \mathrm{Cl}_{2} \mathrm{MDP}$ & $41.1 \pm 1.0$ \\
$5 \times 10^{-7} \mathrm{M} \mathrm{Cl}_{2} \mathrm{MDP}$ & $40.6 \pm 1.6$ \\
\hline
\end{tabular}

All values are means \pm SEM from six determinations.

- Significantly different from control, $P<0.01$.

instances, the labeled particles were pretreated with P-C-P before being added to the wells; in other cases, it was the unlabeled bone that was coated with P-C-P. If P-C-P act primarily by their presence at the cell-bone interface, then only those wells containing labeled bone and P-C-P should show evidence of reduced resorptive activity. In the experiment depicted in Fig. 4, the decrements in apparent resorptive activity were only significant in cultures containing labeled bone pretreated with P-C-P.

We have previously demonstrated that binding of bone by $M \varnothing$ is a prerequisite for resorption and that a lag period of $\sim 8 \mathrm{~h}$ exists between the initiation of

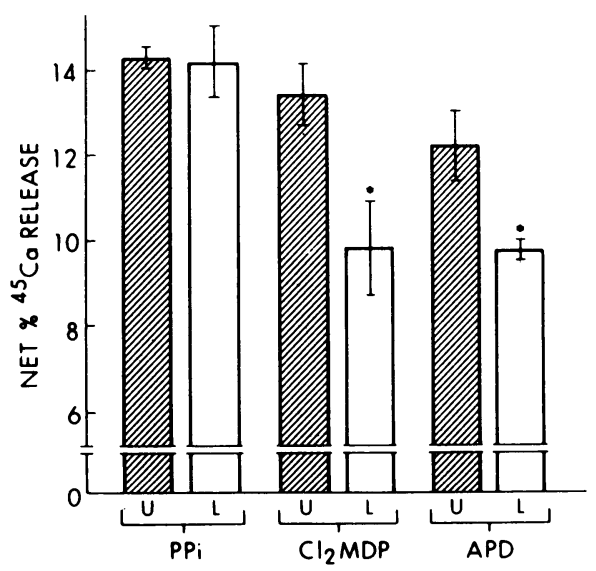

Figure 4 The co-culture of labeled and unlabeled bone "coated" with $\mathrm{Cl}_{2} \mathrm{MDP}$ or APD. In some instances the labeled bone $(\mathrm{L})$ was pretreated $(10 \mathrm{~min})$ with $10^{-5} \mathrm{M} \mathrm{Cl}_{2} \mathrm{MDP}$ or APD; in other cases the unlabeled bone (U) was pretreated. Notice that significant $\left(^{*}\right)$ inhibition of resorption $\left({ }^{45} \mathrm{Ca}\right.$ release) was evident only in those instances where the labeled particles were coated with P-C-P $\left(\mathrm{P}<0.01, \mathrm{Cl}_{2} \mathrm{MDP}\right.$; $P<0.001$, APD). All values represent the mean \pm SEM from six determinations.
TABLE II

Effect of $\mathrm{Cl}_{2} \mathrm{MDP}$ and $\mathrm{APD}$ on the 2-h Attachment of Bone Particles to Cells

\begin{tabular}{cc}
\hline Control & Particles bound \\
\hline & $\%$ \\
& $80.5 \pm 0.9$ \\
$5 \times 10^{-5} \mathrm{M} \mathrm{APD}$ & $81.0 \pm 0.7$ \\
$5 \times 10^{-7} \mathrm{M} \mathrm{APD}$ & $81.8 \pm 0.9$ \\
$5 \times 10^{-5} \mathrm{M} \mathrm{Cl}_{2} \mathrm{MDP}$ & $82.5 \pm 0.4$ \\
$5 \times 10^{-7} \mathrm{M} \mathrm{Cl}_{2} \mathrm{MDP}$ & $83.2 \pm 0.7$ \\
\hline
\end{tabular}

All values are means \pm SEM from six determinations.

binding and the onset of osteolysis (14, and unpublished observations). Table II shows that neither compound interferes with the binding of bone by the cells. However, deferring the introduction of P-C-P until after maximum cell-particle binding is achieved and bone degradation begins, significantly reduces the resorption-inhibiting effect of these compounds (Fig. 5). This effect was most notable with $\mathrm{Cl}_{2} \mathrm{MDP}$ where an 8-h delay totally eliminated the suppressive effect of this P-C-P. APD, on the other hand, continued to be

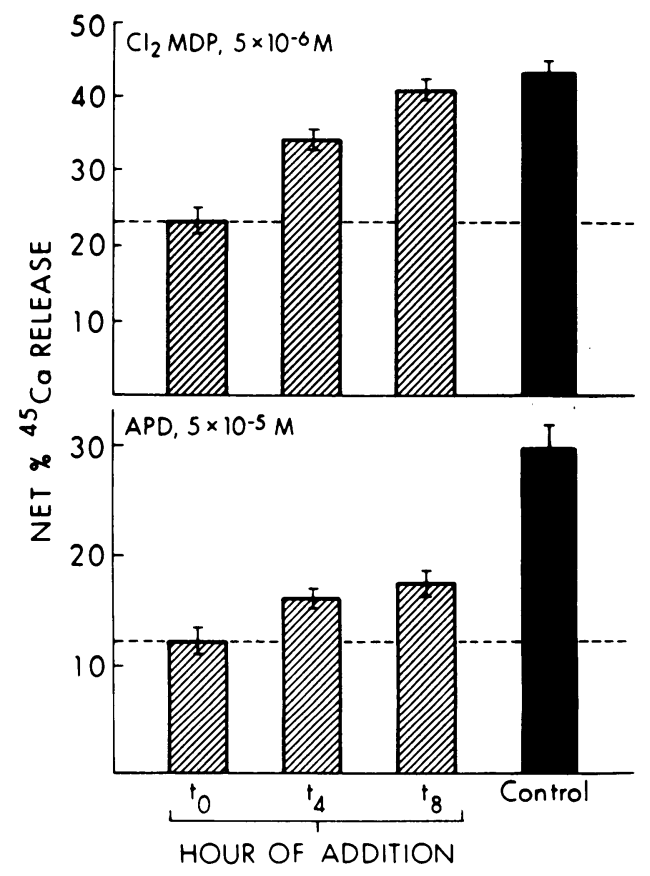

Figure 5 Effect of delayed addition of APD and $\mathrm{Cl}_{2} \mathrm{MDP}$ on the inhibition of ${ }^{45} \mathrm{Ca}$ release by $\mathrm{M} \varnothing$ from devitalized bone particles after $96 \mathrm{~h}$ incubation. Note that in all cases, delaying the introduction of $\mathrm{P}-\mathrm{C}-\mathrm{P}$ renders the compounds significantly less inhibitory $(P<0.01$ to $P<0.001)$, but that the effect is most pronounced with $\mathrm{Cl}_{2} \mathrm{MDP}$. All values represent the mean $\pm \mathrm{SEM}$ from six determinations. 
strongly inhibitory even when introduced after the particle binding phase was completed.

Chambers (18) recently reported that high concentrations of $\mathrm{Cl}_{2} \mathrm{MDP}$ are cytotoxic for murine macrophages. This cytotoxicity was also evident in rat peritoneal celts and likely accounts for all the inhibition of $\mathrm{M} \varnothing$-mediated resorption exhibited by this P-C-P in vitro. For example, as can be seen in Fig. 6, in cultures containing bone particles and treated with $\mathrm{Cl}_{2} \mathrm{MDP}$, for the $96-\mathrm{h}$ assay period, there is a near proportionality between the degree of cytotoxicity (loss of DNA) and the extent of the inhibition. We noted earlier the effectiveness of pretreating bone particles with $\mathrm{Cl}_{2} \mathrm{MDP}$ in suppressing resorption (Fig. 2). The critical importance of the bone particles in contributing to the action of $\mathrm{Cl}_{2} \mathrm{MDP}$ was further documented by experiments in which cytotoxicity was shown to vary as a function of both the amount and particle size of bone added to the cultures. From the experiment depicted in Fig. 7, it can be seen that the decrement in the amount of DNA increases with increasing amounts of bone, and that smaller bone particles are approximately an order of magnitude more effective in enhancing cytotoxicity than are larger ones.

The relationship between cytotoxicity and the inhibition of resorption was much less certain with regard to APD and $\mathrm{Cl}_{2} \mathrm{MDP}$. For example, in contrast to $\mathrm{Cl}_{2} \mathrm{MDP}$, cultures treated continuously with APD exhibit relatively greater inhibition of resorption than loss of cells (Fig. 6). Moreover, and again in distinction

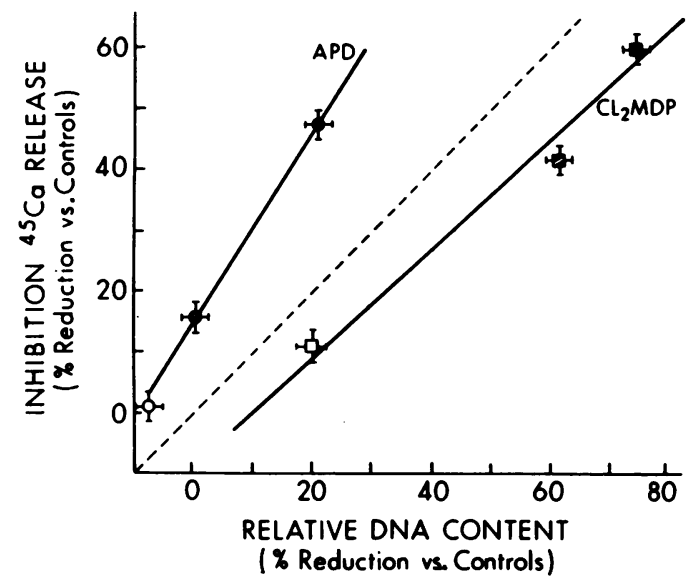

Figure 6 Relationship between the inhibition of ${ }^{45} \mathrm{Ca}$ release and the reduction in DNA content of the $M \varnothing$ population in incubations containing bone particles. The concentrations of APD (circles) and $\mathrm{Cl}_{2} \mathrm{MDP}$ (squares) were $10^{-6}$ $M$ (open symbols), $10^{-5} \mathrm{M}$ (striped symbols), and $10^{-4} \mathrm{M}$ (filled symbols). Notice that with APD, the inhibition of resorption is greater than would be expected on the basis of cytotoxicity (loss of DNA) alone. All values represent the mean $\pm S E M$ from six determinations.

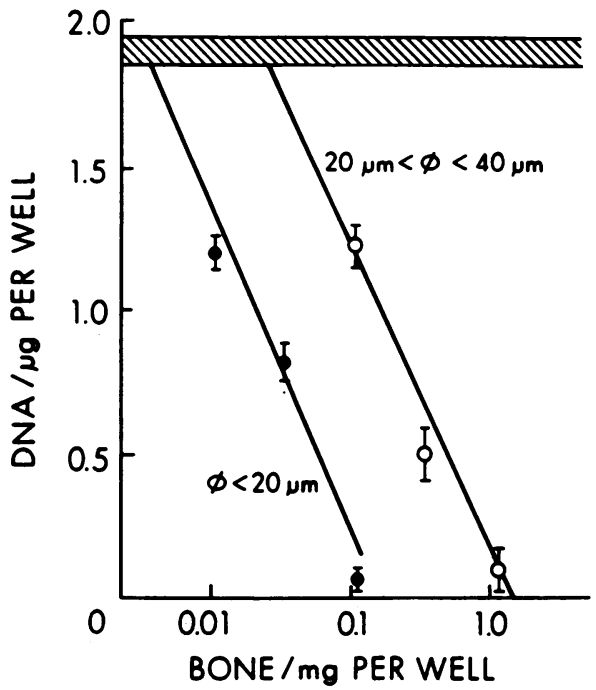

FIgURE $7 \quad \mathrm{Cl}_{2} \mathrm{MDP}$ cytotoxicity as a function of the amount and particle size of bone added to macrophage cultures. (In this figure $\phi$ denotes diameter of bone particles.) Note that increasing the amount of bone leads to increased cytotoxicity (measured as the loss of DNA per well) and that smaller bone particles are more effective in enhancing cytotoxic activity than are larger ones. Each value represents the mean \pm SEM from six replicate cultures.

to $\mathrm{Cl}_{2} \mathrm{MDP}$, the degree of cell death in APD-treated cultures was independent of the mode of presentation of the P-C-P and whether or not bone was present in the wells (Table III). Finally, and perhaps most importantly, APD showed significant inhibition of resorption at concentrations lower than those needed to

TABLE III
$\begin{gathered}\text { Effect of APD and } C l_{2} M D P \text { on DNA Content of Cultures after } \\ 96-h \text { Incubation }\end{gathered}$
DNA/well, $\mu g$

\begin{tabular}{cccc}
\cline { 3 - 4 } Control & $\begin{array}{c}2.76 \pm 0.07 \\
\text { Continuous } \\
\text { exposure, with } \\
\text { bone particles }\end{array}$ & $\begin{array}{c}\text { Preincubation, } \\
\text { with bone } \\
\text { particles }\end{array}$ & $\begin{array}{c}\text { Preincubation } \\
\text { cells (no bone } \\
\text { particles) }\end{array}$ \\
\hline $\mathrm{DAP}$ & & & \\
$10^{-6} \mathrm{M}$ & $3.02 \pm 0.09$ & $2.96 \pm 0.04$ & $2.85 \pm 0.10$ \\
$10^{-5} \mathrm{M}$ & $2.80 \pm 0.05$ & $2.74 \pm 0.06$ & $2.64 \pm 0.07$ \\
$10^{-4} \mathrm{M}$ & $2.18 \pm 0.07 \ddagger$ & $2.21 \pm 0.02 \ddagger$ & $1.96 \pm 0.10 \ddagger$ \\
$\mathrm{Cl}_{2} \mathrm{MDP}$ & & & \\
$10^{-6} \mathrm{M}$ & $2.20 \pm 0.04 \ddagger$ & $2.53 \pm 0.06^{\circ} \cdots$ & - \\
$10^{-5} \mathrm{M}$ & $1.03 \pm 0.10 \ddagger$ & $1.63 \pm 0.06^{\circ} \ddagger^{\circ}$ & - \\
$10^{-4} \mathrm{M}$ & $0.71 \pm 0.10 \ddagger$ & $0.78 \pm 0.07^{\circ} \ddagger^{\circ}$ & - \\
\hline
\end{tabular}

All values are means \pm SEM from six determinations.

- Significantly different from control $P<0.05$.

† Significantly different from control, $P<0.001$. 
affect cell viability (loss of DNA; c.f., Fig. 6), and with a different time course of activity (Fig. 8).

\section{DISCUSSION}

We mentioned previously that P-C-P bind to and limit the in vitro solubility of hydroxylapatite (bone) crystals $(1,10,11)$. It follows from this that P-C-P may inhibit bone resorption by directly increasing the resistance of the mineral phase of bone to degradation (16). However, the inhibition of resorption by P-C-P is also associated with dramatic changes in both osteoclast morphology and in the size of the osteoclast population $(2-4,17)$, indicating that these compounds exert a profound effect upon resorbing cells as well as upon the bone mineral.

To gain further insight into the relative importance of P-C-P action on mineralized bone matrix and resorbing cells, we have assessed the effect of these compounds using an in vitro assay system that permits the independent treatment of the cellular and matrical components of bone resorption. Specifically, we have determined the binding and resorption of isotopically labeled rat bone particles by elicited rat macrophages under conditions where the drugs were present continuously and following the preincubation of the cells or bone particles with P-C-P.

The suppression of ${ }^{45} \mathrm{Ca}$ release in the continuous presence of $\mathrm{Cl}_{2} \mathrm{MDP}$ or APD documents the inhibitory effect of P-C-P on bone resorption in the macrophageresorption system. Moreover, the lack of change in the passive movement of ${ }^{45} \mathrm{Ca}$ in the presence of either compound argues that this inhibition cannot be explained simply by crystal stabilization. Similarly, the effect of P-C-P on resorption does not appear to be due to a diminution in the avidity with which resorbing cells bind the bone particles, a step that we have previously shown to be essential in the resorptive process (14).

On the other hand, our data do indicate that the binding of P-C-P to bone mineral very likely plays an important role in the skeletal action of these compounds, at least with regard to $\mathrm{Cl}_{2} \mathrm{MDP}$. For example, pretreatment of ${ }^{45} \mathrm{Ca}$-labeled bone particles with $\mathrm{Cl}_{2} \mathrm{MDP}$ suppresses subsequent resorptive activity almost as effectively as having the P-C-P present continuously in the culture medium. In addition, the observation that the inhibitory action of P-C-P is reduced by delaying their introduction into the culture suggests that the compounds lose at least some of their effectiveness if they are prevented from accumulating on crystals' surfaces until cell-matrix attachment is completed and resorption initiated. This observation is particularly striking in the case of $\mathrm{Cl}_{2} \mathrm{MDP}$, where an 8-h delay entirely mitigates its inhibitory action. Finally, the data from the experiment utilizing treated unlabeled and labeled bone further establishes that mineral-bound P-C-P can directly suppress resorption without prior release of P-C-P from the bone surface or of some secondary effector substance (monokine) from macrophages.

The proportional diminution in the DNA content of adherent macrophage populations and resorptive activity indicates that cytotoxicity is largely responsible for the inhibitory effect of $\mathrm{Cl}_{2} \mathrm{MDP}$ on bone resorption, as has been previously suggested (18). This cytotoxicity is dependent upon the presence of bone and, as we have shown here, increases when additional

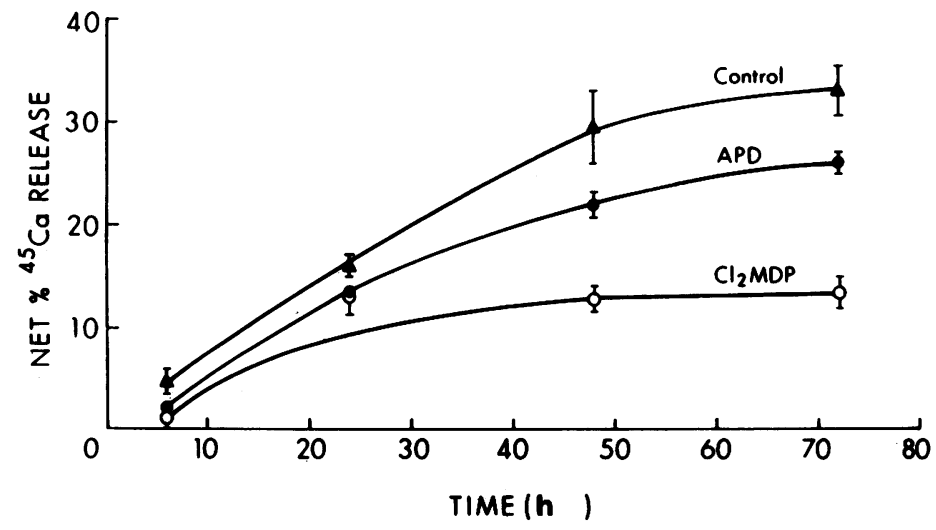

Figure 8 Time course of the inhibition of resorption by $5 \times 10^{-5} \mathrm{M} \mathrm{Cl}_{2} \mathrm{MDP}$ and APD. Note that both P-C-P show marginal inhibitory activity within the first $24 \mathrm{~h}$ of culture and significant inhibition by $48 \mathrm{~h} . \mathrm{Cl}_{2} \mathrm{MDP}$ is clearly more potent than APD and essentially curtails all resorptive activity after the 1 st $\mathrm{d}$ of incubation. In this experiment only $\mathrm{Cl}_{2} \mathrm{MDP}$ proved cytotoxic, reducing culture DNA values by $72 \mathrm{~h}$ to $1.38 \mu \mathrm{g} /$ well vs. $2.13 \pm 0.13$ for controls and $2.05 \pm 0.15$ for APDtreated cultures. Each value represents the mean \pm SEM from six replicate cultures. 
bone particles are added to the cultures. We noted above the importance of bone surfaces in "delivering" $\mathrm{P}-\mathrm{C}-\mathrm{P}$. This aspect of P-C-P action is reinforced by the observation that smaller bone particles, with their substantial surface-to-volume ratio, are significantly more effective in enhancing cytotoxicity than are larger particles (even if the latter are present in much greater amounts).

In contrast to $\mathrm{Cl}_{2} \mathrm{MDP}, \mathrm{APD}$ does not appear to inhibit macrophage-mediated resorption solely by killing the resorbing cells. For example, there is a poor correspondence between the loss of adherent macrophages and the inhibition of resorption in cultures treated with APD, and, in fact, significant inhibition is usually observed in the absence of a demonstrable cytotoxicity. Moreover, when cytotoxicity is encountered, it is at very high concentrations of APD $\left(10^{-4}\right.$ $M)$ and is independent of both the mode of introduction of the P-C-P and whether or not bone is present in the cultures.

APD and $\mathrm{Cl}_{2} \mathrm{MDP}$ do not behave identically in vivo (9) and other differences in the mechanisms of action of these compounds are evident in the present in vitro study. $\mathrm{Cl}_{2} \mathrm{MDP}$ appears to work as a cytotoxin in the presence of bone, and this seems adequate to account for the diminution in macrophage-mediated resorption reported above and, perhaps, in animals treated with this P-C-P. APD, on the other hand, suppresses resorption without killing the resorbing cells and without the intervention by bone. This latter effect is, perhaps, most notable in the delayed introduction experiments, where APD continues to exhibit significant inhibitory action even after the completion of cell-bone binding. Thus, while the precise mechanism of action of APD remains unknown, the fact that it can act directly on sensitive cells may account for the relatively greater in vivo potency exhibited by this compound when compared to other P-C-P, e.g., $\mathrm{Cl}_{2} \mathrm{MDP}$ and EHDP (1-hydroxyethylidene-1,1-bisphosphonate).

\section{ACKNOWLEDGMENTS}

The authors wish to acknowledge the expert technical assistance of Jenny Sadow and Lianne van der Wee-Pals. APD and $\mathrm{Cl}_{2} \mathrm{MDP}$ were kindly donated by Henkel $\mathrm{KGaA}$, Düsseldorf, West Germany.

This work was supported, in part, by National Institutes of Health grant DE-05413 and DE-04629 and by the Foundation for Medical Research (FUNGO), which is subsidized by the Netherlands Organization for the Advancement of Pure Research (ZWO).

\section{REFERENCES}

1. Jung, A., S. Bisaz, and H. Fleisch. 1973. The binding of pyrophosphate and two diphosphonates on hydroxyapatite crystals. Calcif. Tissue Res. 11: 269-280.

2. Schenk, R., W. A. Merz, R. Mühlbauer, R. G. G. Russell, and H. Fleisch. 1973. Effects of ethane-1-hydroxy-1,1- diphosphonate (EHDP) and dichloromethylene diphosphonate $\left(\mathrm{Cl}_{2} \mathrm{MDP}\right)$ on the calcification and resorption of cartilage and bone in the tibial epiphysis and metaphysis of rats. Calcif. Tissue Res. 11: 196-214.

3. Miller, S. C., and W. S. S. Jee. 1979. The comparative effects of dichloromethylene diphosphonate $\left(\mathrm{Cl}_{2} \mathrm{MDP}\right)$ and ethane-1-hydroxy-1,1-diphosphonate (EHDP) on growth and modeling of the rat tibia. Calcif. Tissue Res. 23: 207-214.

4. Reitsma, P. H., O. L. M. Bijvoet, H. Verlinden-Ooms, and J. A. Van der Wee-Pals. 1980. Kinetic studies of bone and mineral metabolism during treatment with (3-amino-1-hydroxypropylidene)-1,1-bisphosphonate (APD) in rats. Calcif. Tissue Int. 32: 145-157.

5. Frijlink, W. B., O. L. M. Bijvoet, J. Te Velde, and G. Heynen. 1979. Treatment of Paget's disease with (3amino-1-hydroxy propylidene)-1,1-bisphosphonate (APD). Lancet. I: 799-803.

6. Van Breukelen, F. J. M., O. L. M. Bijvoet, and A. T. van Oosterom. 1979. Inhibition of osteolytic bone lesions by (3-amino-1-hydroxypropylidene)-1,1-bisphosphonate (APD). Lancet. I: 803-805.

7. Meunier, P. J., M. F. Chapuy, C. Alexandre, C. Bressot, C. Eduoard, E. Vignon, L. Mathieu, and U. Trechsel. 1979. Effects of disodium dichloromethylene disphosphonate on Paget's disease of bone. Lancet. II: 489-492.

8. Siris, E. S., W. H. Sherman, D. C. Baquiran, J. P. Schlatterer, E. F. Osserman, and R. E. Canfield. 1980. Effects of dichloromethylene diphosphonate on skeletal mobilization of calcium in multiple myeloma. N. Engl. J. Med. 302: 310-315.

9. Bijvoet, O. L. M., W. B. Frijlink, K. Jie, H. Van der Linden, C. J. L. M. Meyer, H. Mulder, H. C. Van Paassen, P. H. Reitsma, J. Te Velde, E. De Vries, and J. P. Van der Wey. 1980. APD in Paget's disease of bone: Role of mononuclear phagocyte system? Arthritis Rheum. 23: 1190-1203.

10. Francis, M. D. 1969. The inhibition of calcium hydroxyapatite crystal growth by polyphosphates. Calcif. Tissue Res. 3: 151-162.

11. Fleisch, H., R. G. G. Russell, and M. D. Francis. 1969. Diphosphonates inhibit hydroxyapatite dissolution in vitro and bone resorption in tissue culture and in vivo. Science (Wash., DC). 165: 1264-1266.

12. Fast, D. K., R. Felix, C. Dowse, W. F. Neuman, and H. Fleisch. 1978. The effects of diphosphonates on the growth and glycolysis of connective tissue cells in culture. Biochem. J. 192: 97-107.

13. Felix, R., and H. Fleisch. 1979. Effect of EHDP and $\mathrm{Cl}_{2} \mathrm{MDP}$ on the metabolism of glucose and fatty acids in cultured calvaria cells. Min. Electrolyte Metab. 2: 223-224.

14. Teitelbaum, S. L., C. C. Stewart, and A. J. Kahn. 1979. Rodent peritoneal macrophages as bone resorbing cells. Calcif. Tissue Int. 27: 255-261.

15. Karsten, U., and A. Wollenberger. 1977. Improvement in the ethidium bromide method for the direct fluorometric estimation of DNA and RNA in cell and tissue homogenates. Anal. Biochem. 77: 464-470.

16. Russell, R. G. G., and H. Fleisch. 1975. Pyrophosphate and diphosphonates in skeletal metabolism. Clin. Orthop. Relat. Res. 108: 241-262.

17. Rowe, D. J., and E. Hausmann. 1976. The alteration of osteoclast morphology by diphosphonate in bone organ culture. Calcif. Tissue Res. 20: 53-60.

18. Chambers, T. J. 1980. Diphosphonates inhibit bone resorption by macrophages in vitro. J. Pathol. 132: 255262. 